\title{
Germline Mutations in DNA Repair Genes in Patients With Metastatic Castration-resistant Prostate Cancer
}

\author{
KLAUDIA HOLECKOVA ${ }^{1,2}$, KATARINA BALUCHOVA ${ }^{3}$, MARK HIVES $^{4}$, \\ LUDOVIT MUSAK ${ }^{2}$, JAN KLIMENT SR. $^{1}$ and MARIA SKERENOVA ${ }^{2,5}$ \\ ${ }^{1}$ Department of Urology, Jessenius Faculty of Medicine in Martin and University Hospital Martin, \\ Comenius University in Bratislava, Martin, Slovak Republic; \\ ${ }^{2}$ Biomedical Center Martin, Jessenius Faculty of Medicine in Martin, \\ Comenius University in Bratislava, Martin, Slovak Republic; \\ ${ }^{3}$ OncoLab Diagnostics, Technologie- und Forschungszentrum, Vienna, Austria; \\ ${ }^{4}$ Department of Medical Biochemistry, Jessenius Faculty of Medicine in Martin, \\ Comenius University in Bratislava, Martin, Slovak Republic; \\ ${ }^{5}$ Department of Clinical Biochemistry, Jessenius Faculty of Medicine in Martin and University Hospital Martin, \\ Comenius University in Bratislava, Martin, Slovak Republic
}

\begin{abstract}
Background/Aim: The aim of this study was to analyse the genetic profiles of metastatic castrationresistant prostate cancer $(m C R P C)$ by using next generation sequencing to identify variants with pathogenic potential in nine DNA repair genes - BRCA1, BRCA2, RAD50, RAD51, RAD51C/D, ATM and ATR. Materials and Methods: Isolated genomic DNA from peripheral blood of 50 patients with $\mathrm{mCRPC}$ was used for the sequencing of 111 genes associated with hereditary cancer on an Illumina platform. Identified variants were tested in Integrative Genomic Viewer, their clinical significance confirmed in databases and their potential impact on protein function predicted by in silico tools. Results: From nine analysed DNA repair genes, we identified 14 relevant variants; three pathogenic variants - BRCA2 (rs80359306), RAD50 (rs786201531) and ATM (rs 1555099760), and eleven other variants with pathogenic potential. Conclusion: The pathogenic variants identified in this study are located in evolutionarily conserved regions of proteins and are highly likely to affect DNA repair efficiency.
\end{abstract}

This article is freely accessible online.

Correspondence to: Skerenova Maria, Biomedical Center Martin, Jessenius Faculty of Medicine in Martin, Comenius University in Bratislava, Malá Hora 4, 03601 Martin, Slovak Republic. Tel: +421 432633480, e-mail: maria.skerenova@uniba.sk

Key Words: Prostate cancer, next generation sequencing, DNA repair genes, germline mutations.
Prostate cancer (PC) is the second most common oncological disease in Slovakia, one of the major medical problems of the male population occurring in ages over 50 years. Despite extensive studies of PC, the exact cause is not yet known.

Based on DNA change, certain cells in prostate start to grow and proliferate without control which mostly results in tumour formation. Upon DNA damage, DNA repair mechanisms are activated to repair damaged DNA and thus prevent cancer. Some DNA changes can either be inherited or acquired during a lifetime. According to American Cancer Society, more than $10 \%$ of PC cases represent hereditary cancer, in which inherited genes play an important role. It has long been known that heredity plays a significant role in PC. Men with a family history of PC have a greater risk of developing PC (1). Germline mutations in DNA repair genes are linked to poor prognosis, early onset, increased aggressiveness, drug treatment response, higher possibility of early development of CRPC and the course of the disease itself (2).

In our study, we focused on changes in DNA repair genes, that may greatly influence DNA repair mechanisms as well as genomic integrity. Deregulation of repair mechanisms can cause disruption of gene function, accelerated aging and higher risk for cancer (3). There are five major DNA repair pathways whose role is to repair and eliminate singlestranded (SSB) and double-stranded (DSB) DNA breaks. We focused on genes involved in homologous recombination (HR). Approximately $20-25 \%$ of mCRPC are mostly linked with defects in HR genes (4), implying the importance of HR as a major DNA damage repairing pathway, monitoring genomic stability and preventing cells from being transformed into cancerous cells (5). 
Table I. Characteristics of identified variants in DNA repair genes.

\begin{tabular}{|c|c|c|c|c|c|c|c|}
\hline Gene type & Mutation type & HGMD & Coding sequence & $\begin{array}{l}\text { Protein sequence } \\
\text { in this study }\end{array}$ & dbSNP ID & Frequency & gnomAD $(\%)$ \\
\hline \multirow[t]{4}{*}{$B R C A 2$} & Frameshift indel & DM? & c.10095delCinsGAATTATATCT & p.Ser3366AsnfsTer5 & rs276174803 & $1 / 50$ & N/A \\
\hline & Frameshift insertion & $\mathrm{DM}$ & c.1813_1814insA & p.Ile605AsnfsTer11 & rs80359306 & $1 / 50$ & 0.0009 \\
\hline & Missense mutation & DM? & c. $7057 \mathrm{G}>\mathrm{C}$ & p.Gly2353Arg & rs80358935 & $1 / 50$ & 0.0062 \\
\hline & Missense mutation & DM? & c. $6706 \mathrm{G}>\mathrm{A}$ & p.Glu2236Lys & rs41293503 & $1 / 50$ & 0.0062 \\
\hline \multirow[t]{2}{*}{$P A L B 2$} & Missense mutation & $\mathrm{DP}$ & c. $2993 \mathrm{G}>\mathrm{C}$ & p.Gly998Ala & rs 45551636 & $4 / 50$ & 2.2200 \\
\hline & Missense mutation & DM? & c. $2794 \mathrm{G}>\mathrm{A}$ & p.Val932Met & rs 45624036 & $1 / 50$ & 0.6590 \\
\hline \multirow[t]{2}{*}{ RAD50 } & Frameshift insertion & $\mathrm{DM}$ & c.541_542insT & p.Ser181PhefsTer7 & rs786201531 & $1 / 50$ & 0.0026 \\
\hline & Missense mutation & N/A & c. $733 \mathrm{G}>\mathrm{A}$ & p.Glu245Lys & rs797044753 & $1 / 50$ & N/A \\
\hline RAD51C & Missense mutation & DM? & c. $859 \mathrm{~A}>\mathrm{G}$ & p.Thr287Ala & rs 28363317 & $1 / 50$ & 0.9610 \\
\hline \multirow[t]{3}{*}{ ATM } & Frameshift deletion & $\mathrm{DM}$ & c.4451del & p.Met1484ArgfsTer15 & rs1555099760 & $1 / 50$ & N/A \\
\hline & Missense mutation & DM? & c. $6067 \mathrm{G}>\mathrm{A}$ & p.Gly2023Arg & rs11212587 & $1 / 50$ & 0.2380 \\
\hline & Missense mutation & DM? & c. $7475 \mathrm{~T}>\mathrm{G}$ & p.Leu2492Arg & rs56399857 & $1 / 50$ & 0.0211 \\
\hline \multirow[t]{2}{*}{$A T R$} & Frameshift deletion & N/A & c.975_976del & p.Val327HisfsTer3 & rs 759554602 & $1 / 50$ & 0.0018 \\
\hline & Missense mutation & N/A & c. $4592 \mathrm{~A}>\mathrm{G}$ & p.His1531Arg & rs200070057 & $1 / 50$ & 0.0259 \\
\hline
\end{tabular}

The first activated complex involved in the recognition of DSB is the MRE11-RAD50-NBS1 (MRN) complex, which due to its DNA-binding ability adheres to DNA damage sites. DSB also activates the ATM and ATR kinases whose role lies in coordinating cell cycle checkpoint and DNA repair pathways. For the final homology-directed repair (HDR) of DNA breaks is crucial the formation of RAD51 nucleofilaments mediated by checkpoint regulation factors PALB2 and BRCA2, which cooperate with BRCA1 (6). The RAD51 nucleofilaments, along with paralogues RAD51C/D, mediate the homology search, prepare and use sister chromatid as a template for a new DNA strand synthesis (4).

\section{Materials and Methods}

The study group included 50 mCRPC patients with unknown records of the hereditary origin of prostate cancer [mean age $=71.64$, median age $=71.5$; mean prostate-specific antigen $(P S A)=6.06 \mathrm{ng} / \mathrm{ml}$, median PSA=19.29 ng/ml]. This study was approved by the Ethical Committee at Jessenius Faculty in Medicine in Martin, Comenius University in Bratislava.

Genomic DNA from buffy coat (approx. $200 \mu \mathrm{l}$ ) was purified using the QIAamp DNA Blood Mini Kit (Qiagen, Hilden, Germany). Quality and quantity of the DNA were measured on NanoDrop ${ }^{\mathrm{TM}} 2000$ Spectrophotometer (Thermo Fisher Scientific, MA, USA). The Qubit ${ }^{\circledR}$ 3.0 Fluorometer (Thermo Fisher Scientific) was used for subsequently dilution of DNA samples to concentration $20 \mathrm{ng} / \mu \mathrm{l}$ required for the preparation of NGS library. NGS was performed by the external supplier Sistemas Genómicos (Valencia, Spain). The analysed panel GeneSGKit ${ }^{\circledR}$ contained 111 genes related to hereditary cancer of heterogeneous origin. Their protein-coding exons, flanking regions and introns were sequenced using HiSeq 2500 System (Illumina, CA, USA). Raw sequencing data were analysed through GeneSystems $@$ (Sistemas Genómicos, Valencia, Spain) and a VCF file was created for every patient. Identified variants with potential clinical significance were tested in Integrative Genomic Viewer (IGV) and their clinical significance was confirmed in VarSome search engine (7). To predict the potential impact of amino acid substitution on protein function we used in silico predictor tools SIFT (8) and PolyPhen-2 (9). The source of protein sequence expressed from individual genes used for in silico predictions was UniProt (10). To evaluate indel variants for their disease-causing potential we used MutationTaster (11).

\section{Results}

We examined gene profiles of 50 patients with mCRPC for the presence and frequency of germline mutations in nine DNA-repair genes - BRCA1, BRCA2, PALB2, RAD50, $R A D 51$ and its paralogues RAD51C and RAD51D, ATM and $A T R$. With respect to the reference genome (GRCh38.p7 assembly), individual genes contained multiple variants with mean value 17.44 variants per gene: missense 48 (30.6\%), frameshift $5(3.2 \%)$, in frame $1(0.6 \%)$, synonymous 26 $(16.6 \%)$ and intron $77(49.0 \%)$. Average sequencing depth was 365 reads per gene (minimum 171 reads for ATM, maximum 579 reads for $B R C A 1$ ). From all 157 variants, 14 variants with pathogenic potential according to American College of Medical Genetics and Genomics (ACMG) classification implemented into the automated criteria and rules in VarSome, were filtered. The Table I lists Human Genome Variation Society (HGVS) names and other characteristics of all filter passed variants in our patient sample, and in the Table II we present the characteristics of the pathogenic potential and clinical significance of these variants.

$B R C A 1$. In BRCAl gene, we detected 10 missense variants; eight in exon 10 (rs1799950, rs4986850, rs28897683, rs799917, rs16941, rs4986852, rs16942 and rs28897689) and two in exon 15 (rs1799966, rs1799967). The first nine variants mentioned do not lie in any of the important BRCA1 
Table II. Characteristics of identified variants in DNA repair genes.

\begin{tabular}{|c|c|c|c|c|c|c|}
\hline \multirow[b]{2}{*}{ Gene type } & \multirow[b]{2}{*}{ dbSNP ID } & \multicolumn{2}{|c|}{ In-silico predictions } & \multirow[b]{2}{*}{ MutationTaster } & \multicolumn{2}{|c|}{ Clinical significance } \\
\hline & & SIFT & PolyPhen-2 & & VarSome* & ClinVar \\
\hline \multirow[t]{4}{*}{$B R C A 2$} & rs276174803 & N/A & N/A & Disease causing & PVS1, PM2 & Likely benign \\
\hline & rs80359306 & N/A & N/A & Disease causing & PVS1, PM1, PM2, PP5 & Pathogenic \\
\hline & rs80358935 & Probably damaging (0.992) & Damaging (0.04) & Polymorphism & $\mathrm{PM} 1^{\mathrm{m}}, \mathrm{PM} 2^{\mathrm{m}}, \mathrm{PP} 3^{\mathrm{s}}$ & Likely benign \\
\hline & rs41293503 & Probably damaging (1.00) & Damaging (0.00) & Disease causing & $\mathrm{PM} 1^{\mathrm{m}}, \mathrm{PM} 2^{\mathrm{m}}, \mathrm{PP} 3^{\mathrm{s}}$ & VUS \\
\hline \multirow[t]{2}{*}{$P A L B 2$} & rs 45551636 & Deleterious (0.003) & $\begin{array}{c}\text { Probably damaging } \\
\text { (1.0) }\end{array}$ & Polymorphism & $\begin{array}{l}\mathrm{PM} 1^{\mathrm{m}}, \mathrm{PM} 2^{\mathrm{m}} \\
\mathrm{BS} 1, \mathrm{BS} 2, \mathrm{BP} 6\end{array}$ & Likely benign \\
\hline & rs 45624036 & Tolerated $(0.11)$ & $\begin{array}{c}\text { Probably damaging } \\
(0.993)\end{array}$ & Disease causing & $\begin{array}{c}\mathrm{PM} 1^{\mathrm{m}}, \mathrm{PM} 2^{\mathrm{m}}, \mathrm{BS} 1 \\
\mathrm{BS} 2, \mathrm{BP} 6\end{array}$ & $\begin{array}{l}\text { Benign/likely } \\
\text { Benign }\end{array}$ \\
\hline \multirow[t]{2}{*}{ RAD50 } & rs786201531 & N/A & N/A & Disease causing & $\mathrm{PVS}_{1}, \mathrm{PP} 3^{\mathrm{s}}, \mathrm{PP}^{\mathrm{m}}, \mathrm{BS} 2$ & Pathogenic \\
\hline & rs797044753 & Tolerated $(0.41)$ & Benign (0.268) & Disease causing & $\mathrm{PM}^{\mathrm{m}}, \mathrm{PP} 3 \mathrm{~s}, \mathrm{BP} 1$ & VUS \\
\hline$R A D 51 C$ & rs28363317 & Tolerated $(0.20)$ & $\begin{array}{c}\text { Probably damaging } \\
\qquad(0.988)\end{array}$ & Polymorphism & $\begin{array}{l}\mathrm{PM} 1^{\mathrm{m}}, \mathrm{PP}^{\mathrm{s}}, \mathrm{PP}^{\mathrm{m}}, \\
\mathrm{BS} 1, \mathrm{BS} 2, \mathrm{BP} 6\end{array}$ & Likely benign \\
\hline \multirow[t]{3}{*}{ ATM } & rs 1555099760 & N/A & N/A & Disease causing & PVS1, PM2m ${ }^{\text {PP5 }}{ }^{\mathrm{m}}$ & Pathogenic \\
\hline & rs11212587 & Tolerated (0.09) & Benign (0.00) & Disease causing & $\mathrm{PM}^{\mathrm{m}}, \mathrm{PP}^{\mathrm{s}}, \mathrm{BS} 1, \mathrm{BP} 6$ & VUS \\
\hline & rs56399857 & Deleterious $(0.00)$ & $\begin{array}{c}\text { Possibly damaging } \\
\text { (0.993) }\end{array}$ & Disease causing & $\mathrm{PM} 1^{\mathrm{m}}, \mathrm{PP} 3^{\mathrm{s}}, \mathrm{BS} 1, \mathrm{BP} 6$ & VUS \\
\hline \multirow[t]{2}{*}{$A T R$} & rs759554602 & N/A & N/A & Disease causing & $\mathrm{PVS} 1, \mathrm{PM} 2^{\mathrm{m}}, \mathrm{PP} 3^{\mathrm{s}}$ & N/A \\
\hline & rs 200070057 & Deleterious (0.03) & Probably damaging (1.0) & Disease causing & $\mathrm{PP}^{\mathrm{s}}, \mathrm{BP} 1$ & N/A \\
\hline
\end{tabular}

*PM4: Pathogenic, moderate; BP6: Benign, moderate; PVS1: Pathogenic, very strong; PM1: Pathogenic, very strong; PM1: Pathogenic, moderate; PM2: Pathogenic moderate, PP5: Pathogenic, very strong; PM1 ${ }^{\mathrm{m}}$ : Pathogenic, moderate; PM2 ${ }^{\mathrm{m}}$ : Pathogenic moderate; PP35: Pathogenic, supporting; BS1: Benign, strong; BS2: Benign, strong; BP6: Benign, strong; PP5m: Pathogenic, moderate; BP1: Benign, supporting.

domains, but in mutational hot spots of 31 base-pairs length, which have been connected to early onset and high histological grade of cancer (12). The pathogenicity of variants in these areas varies between 54.9-81.0\% and include up to 28 classified variants mostly with pathogenic status (7). Only the benign missense variant p.Met1652Ile (rs1799967) is located in BRCT1 domain, one of the integral signalling modules in DNA damage response (13). According to VarSome and ClinVar all BRCAl variants identified in this study are benign or likely benign, deleterious effect (SIFT and PolyPhen-2) was predicted for only three variants, p.Thr826Lys, p.Ser1040Asn and p.Ser1613Cys, but MutationTaster evaluated them as frequent polymorphisms.

$B R C A 2$. In $B R C A 2$ gene, we analysed one pathogenic frameshift variant (rs80359306) in exon 10, localised in the PALB2-binding domain, which is essential for many functions, such as G2/M checkpoint, protection of replication fork and DNA breaks repair by homologous recombination (14). In exon 11, we detected three missense variants (rs41293503, rs1799944, rs4987117), which are located in the RAD51-binding domain at the $\mathrm{N}$-terminus of the protein. RAD51 and BRCA2 provide exchange of genetic information between damaged and sister chromatids (15). In silico tools predicted that only the variant p.Glu2236Lys (rs41293503) may be associated with disease cause in the
Human Gene Mutation Database (HGMD), while other databases cannot determine the exact clinical significance of this variant. In exon 14, we found another missense variant p.Gly2353Arg (rs80358935), located in DNA-binding domain, which is an integral part of homologous recombination facilitating the binding of the recombination protein RAD51 at DNA breaks (15). Regarding the frameshift indel variant (rs276174803) in exon 27 at position c.10095 with deletion of one cytosine and insertion of 11 bases (C/GAATTATATCT), the formation of a stop codon and subsequent termination of protein synthesis is predicted.

$P A L B 2$. In each of exons 8 and 9 of the $P A L B 2$ gene (partner and localizer of $B R C A 2$ ), we found two benign missense variants: p.Val932Met (rs45624036) and p.Gly998Glu (rs45551636).

$R A D 50$. In the coiled-coil domain of RAD50, we detected the pathogenic frameshift variant p.Ser181PhefsTer7 (rs786201531), which terminates the protein at position 188 and the missense variant of uncertain significance (VUS) p.Glu245Lys (rs797044753).

RAD51 and its paralogues. We did not find any potentially pathogenic variants in the $R A D 51$ gene and its paralogue $R A D 51 D$. However, in exon 6 of the paralogue $R A D 51 C$, we found the likely benign missense variant p.Thr287Ala 
(rs28363317) that is located at the C-terminal Walker B motif ATPase domain.

ATM. In the HEAT repeat segment of ATM, we detected the pathogenic frameshift variant p.Met1484ArgfsTer15 (rs1555099760) that terminates ATM protein at position 1499 and thus significantly truncates the protein by 1557 amino acids and two benign missense variants, p.Phe858Leu (rs1800056) and p.Pro1054Arg (rs1800057). In the important regulatory FAT domain, we found one missense VUS p.Gly2023Arg (rs11212587). In the PI3K domain, we found the likely benign missense variant p.Leu2492Arg (rs56399857) with deleterious prediction in SIFT, PolyPhen2 and also in MutationTaster.

ATR. We found two variants in the $\mathrm{N}$-terminal HEAT repeat segment of ATR; the pathogenic frameshift variant p.Val327HisfsTer3 (rs759554602), which truncates the protein from the original 2644 amino acids to 330 and the missense VUS p.His1531Arg (rs200070057) with deleterious predictions by SIFT, PolyPhen-2 and also in MutationTaster.

\section{Discussion}

Despite the rapid development of new technologies that allow us to observe the profile of the human genome, the genes predisposing to prostate cancer are largely unknown. In this study, we examine profiles of DNA damage repair (DDR) genes in which defects are more prevalent than previously predicted. Recent insights showed that approx. $23 \%$ of mCRPC patients are carriers of somatic/germline mutations in DDR genes, such as BRCA1/2, PALB2, CHEK2, ATM (16) and $F A N C A$ and $R A D 51$ paralogues (17). It has been suggested that DDR defects may be involved in the development of carcinogenesis, disease progression and higher aggressiveness $(16,18)$. In terms of treatment, for mCRPC patients with germline mutations in DDR genes, drugs like docetaxel, abiraterone, enzalutamide and others have been developed and rapidly improved survival, but there remains a need to develop therapies to improve clinical outcomes (16). Several studies have demonstrated that the hereditary component of PC is one of the strongest risk factors. Numerous germline mutations in $B R C A 1$ and $B R C A 2$ genes may increase the risk of prostate cancer (1). Approximately $5.3 \%$ of prostate cancer patients carrying germline mutations in $B R C A 2$ are linked to poor prognosis and early onset (age $<55$ years), higher Gleason score $(>8)$, elevated PSA, more aggressive phenotype and poor clinical outcomes $(1,19,20)$.

In our study, we identified 14 variants having a pathogenic status in VarSome, but only three of them have pathogenic status in ClinVar. Each of the pathogenic frameshift variants is located in a different gene; p.Ile605AsnfsTer11 (BRCA2), p.Ser181PhefsTer7 (RAD50) and p.Met1484ArgfsTer15
(ATM). The frameshift variant p.Ile605AsnfsTer11 (rs80359306) was multiple times associated with familial prostate cancer $(19,21,22)$, as well as with breast and ovarian cancer. Through the creation of a stop codon at position 616 and protein truncation, there has been predicted to cause loss of protein (23). Nykamp et al. have found that the truncating variant p.Ser181PhefsTer7 in RAD50 that we detected in heterozygous status, is lethal or severe (24). These variants may also have the potential to disrupt the communication between the enzymatic domains and functions of the highly conserved MRN protein complex. However, they have not been associated with RAD50-related disease. In exon 30 of $A T M$, we identified the pathogenic frameshift variant p.Met1484ArgfsTer15 (rs1555099760) that causes a premature truncation of ATM protein, which binds to the MRN complex (25).

In addition to these pathogenic variants, we identified other variants with the potential to affect protein functions in DNA repair mechanisms. The variants identified in genes $B R C A 1, R A D 51$ and $R A D 51 D$ were not included in any results table because their pathogenicity was not demonstrated by the in silico tools or listed in databases. In $B R C A 2$, we identified one frameshift indel variant in heterozygous status. It starts at position 10095 by deleting one cytosine and inserting 11 bases GAATTATATCT resulting in premature termination of translation in the very C-terminus of BRCA2 protein. Wojcik et al. have classified this variant as non-pathogenic, however, Balabas et al. and Ratajska et al. have suggested an association of the variant p.Ser3366AsnfsTer5 with familial aggregation of breast and/or ovarian cancer (26-28).

We identified two missense variants in PALB2; p.Gly998Glu and p.Val932Met. Both are located at the Cterminus of the WD40 domain, whose role is direct binding of $R A D 51 C$ and BRCA2 in the process of HR. The protein PALB2 is indispensable for the HR pathway, and it is also considered as a linker between BRCA1 and BRCA2 (29).

There have not been many studies dealing with the association between germline mutations and prostate cancer in $R A D 51$, but $R A D 51$ and XRCC3 polymorphisms may be important for the development of PC which by affecting the DNA repair process and increasing the susceptibility to neoplastic transformation (30). We identified one missense variant p.Thr287Ala (rs28363317) in $R A D 51 C$ associated with PC (31) with possible loss of protein function prediction, generally considered as non-pathogenic and likely benign (31-33). This variant is located at the C-terminal Walker B motif ATPase domain. Alterations in this domain can decrease the ability to repair DNA interstrand crosslinks by RAD51 paralogues and gene XRCC2 (34).

We identified two missense variants in ATM; the p.Gly2023Arg which involves the alteration of a conserved nucleotide with unknown clinical significance $(35,36)$, and 
the p.Leu2492Arg with a predicted deleterious effect (SIFT, PolyPhen-2) on the ATM protein henceforth referred to as a VUS (37). This variant is located in the PI3K domain responsible for the phosphorylation of BRCA1, p53 and other proteins (38).

In the ATR, which is considered to be a DNA damage sensor, we detected the p.Val327HisfsTer3 variant, which is likely a pathogenic frameshift that causes premature truncation of the protein and loss of the main protein function; and the missense variant p.His1531Arg with deleterious outcome and prediction of possible disruption of protein function. There are no records of these two variants in the literature.

To conclude, we identified multiple germline mutations in DNA repair genes involved in homologous recombination pathway. These variants may have the potential to reduce or cause protein dysfunction, and have been associated with more aggressive phenotype of PC and earlier onset of mCRPC. Detection of relevant pathogenic variants in these genes would lead to earlier diagnosis of PC and would allow clinicians to set earlier, more targeted treatment for patients with a family predisposition or patients in the first stages of PC.

\section{Conflicts of Interest}

The Authors confirm that there are no conflicts of interest in regard to this study.

\section{Authors' Contributions}

$\mathrm{KH}$ and $\mathrm{KB}$ conceived the study and were in charge of overall direction and planning. $\mathrm{KH}$ analysed the data, performed literature reviews and drafted the manuscript in consultation with $\mathrm{MH}, \mathrm{LM}$, JK and MS. JK provided samples from Urology Clinic. All Authors discussed the results and contributed to the final manuscript.

\section{Acknowledgements}

This study was supported by the Agency of Ministry of Education, Science, Research and Sport of Slovakia by the Slovak Research and Development Agency under the contract no. APVV-15-0181 and by the Grant of the Comenius University no. UK/26/2019.

\section{References}

1 Zhen JT, Syed J, Nguyen KA, Leapman MS, Agarwal N, Brierley K, Llor X, Hofstatter E and Shuch B: Genetic testing for hereditary prostate cancer: Current status and limitations: Germline testing for prostate cancer. Cancer 124: 3105-3117, 2018. PMID: 29669169. DOI: 10.1002/cncr.31316

2 Nombela P, Lozano R, Aytes A, Mateo J, Olmos D and Castro E: BRCA2 and other DDR genes in prostate cancer. Cancers 11: 352, 2019. PMID: 30871108. DOI: 10.3390/cancers11030352

3 Ronen A and Glickman BW: Human DNA repair genes. Environ Mol Mutagen 37: 241-283, 2001. PMID: 11317342. DOI: 10.1002/em.1033
4 Athie A, Arce-Gallego S, Gonzalez M, Morales-Barrera R, Suarez C, Casals Galobart T, Hernandez Viedma G, Carles J and Mateo J: Targeting DNA repair defects for precision medicine in prostate cancer. Curr Oncol Rep 21, 2019. PMID: 30919167. DOI: $10.1007 / \mathrm{s} 11912-019-0790-6$

5 Prakash R, Zhang Y, Feng W and Jasin M: Homologous recombination and human health: The roles of BRCA1, BRCA2, and associated proteins. Cold Spring Harb Perspect Biol 7: a016600, 2015. PMID: 25833843. DOI: 10.1101/cshperspect. a016600

6 Uziel T, Lerenthal Y, Moyal L, Andegeko Y, Mittelman L and Shiloh Y: Requirement of the MRN complex for ATM activation by DNA damage. EMBO J 22: 5612-5621, 2003. PMID: 14532133. DOI: $10.1093 / \mathrm{emboj} / \mathrm{cdg} 541$

7 Kopanos C, Tsiolkas V, Kouris A, Chapple CE, Albarca AM, Meyer R and Massouras A: VarSome: the human genomic variant search engine. Bioinformatics 35: 1978-1980, 2019. PMID: 30376034. DOI: 10.1093/bioinformatics/bty897

8 Vaser R, Adusumalli S, Leng SN, Sikic M and Ng PC: SIFT missense predictions for genomes. Nat Protocols 11: 1-9, 2016. PMID: 26633127. DOI: 10.1038/nprot.2015.123

9 Adzhubei IA, Schmidt S, Peshkin L, Ramensky VE, Gerasimova A, Bork P, Kondrashov AS and Sunyaev SR: A method and server for predicting damaging missense mutations. Nat Methods 7: 248-249, 2010. PMID: 20354512. DOI: 10.1038/nmeth0410248

10 The UniProt Consortium: UniProt: a worldwide hub of protein knowledge. Nucleic Acids Res 47: D506-D515, 2019. PMID: 30395287. DOI: $10.1093 /$ nar/gky1049

11 Schwarz JM, Cooper DN, Schuelke M and Seelow D: MutationTaster2: mutation prediction for the deep-sequencing age. Nat Methods 11: 361-362, 2014. PMID: 24681721. DOI: $10.1038 /$ nmeth 2890

12 Sun L, Liu J, Wang S, Chen Y and Li Z: Prevalence of BRCA1 gene mutation in breast cancer patients in Guangxi, China. Int $\mathrm{J}$ Clin Exp Pathol 7: 6262-6269, 2014. PMID: 25337278.

13 Leung CCY and Glover JNM: BRCT domains: Easy as one, two, three. Cell Cycle 10: 2461-2470, 2011. PMID: 21734457. DOI: $10.4161 / \mathrm{cc} .10 .15 .16312$

14 Hartford SA, Chitella R, Ding X, Vyas A, Martin B, Burkett S, Haines DC, Southon E, Tessarokko L and Sharan SK: Interaction with PALB2 is essential for maintenance of genomic integrity by BRCA2. PLoS Genet 12: e1006236, 2016. PMID: 27490902. DOI: 10.1371/journal.pgen.1006236

15 Nicolai C, Ehlén Å, Martin C, Zhang X and Carreira A: A second DNA binding site in human BRCA2 promotes homologous recombination. Nat Commun 7: 12813, 2016. PMID: 27628236. DOI: 10.1038/ncomms12813

16 Banks P, Xu W, Murphy D, James P and Sandhu S: Relevance of DNA damage repair in the management of prostate cancer. Curr Probl Cancer 41: 287-301, 2017. PMID: 28712484. DOI: 10.1016/j.currproblcancer.2017.06.001

17 Petrovics G, Price DK, Lou H, Chen Y, Garland L, Bass S, Jones K, Kohaar I, Ali A, Ravindranath L, Young D, Cullen J, Dorsey TH, Sesterhenn IA, Brassell SA, Rosner IL, Ross D, Dahut W, Ambs S, Figg WD, Srivastava S and Dean M: Increased frequency of germline BRCA2 mutations associates with prostate cancer metastasis in a racially diverse patient population. Prostate Cancer Prostatic Dis 22: 406-410, 2019. PMID: 30542053. DOI: 10.1038/s41391-018-0114-1 
18 Kaikkonen E, Ettala O, Nikulainen I, Taimen P, Lehtinen I, Boström PJ, Kellokumpu-Lehtinen P-L and Schleutker J: ANO7 rs77559646 is associated with first-line docetaxel treatment response in metastatic castration-resistant prostate cancer. Anticancer Res 39: 5353-5359, 2019. PMID: 31570429. DOI: 10.21873/anticanres.13728

19 Ibrahim M, Yadav S, Ogunleye F and Zakalik D: Male BRCA mutation carriers: clinical characteristics and cancer spectrum. BMC Cancer 18: 179, 2018. PMID: 29433453. DOI: 10.1186/ s12885-018-4098-y

20 Castro E and Eeles R: The role of BRCA1 and BRCA2 in prostate cancer. Asian J Androl 14: 409-414, 2012. PMID: 22522501. DOI: $10.1038 / a j a .2011 .150$

21 Pritzlaff M, Summerour P, McFarland R, Li S, Reineke P, Dolinsky JS, Goldgar DE, Shimelis H, Couch FJ, Chao EC and LaDuca H: Male breast cancer in a multi-gene panel testing cohort: insights and unexpected results. Breast Cancer Res Treat 161: 575-586, 2017. PMID: 28008555. DOI: 10.1007/s10549016-4085-4

22 Kote-Jarai Z, Leongamornlert D, Saunders E, Tymrakiewicz M, Castro E, Mahmud N, Guy M, Edwards S, O’Brien L, Sawyer E, Hall A, Wilkinson R, Dadaev T, Goh C, Easton D, Goldgar $\mathrm{D}$ and Eeles R: BRCA2 is a moderate penetrance gene contributing to young-onset prostate cancer: implications for genetic testing in prostate cancer patients. Br J Cancer 105: 1230-1234, 2011. PMID: 21952622. DOI: 10.1038/bjc.2011.383

23 Blay P, Santamaría I, Pitiot AS, Luque M, Alvarado MG, Lastra A, Fernández Y, Paredes Á, Freije JM and Balbín M: Mutational analysis of BRCA1 and BRCA2 in hereditary breast and ovarian cancer families from Asturias (Northern Spain). BMC Cancer 13: 243, 2013. PMID: 23683081. DOI: 10.1186/1471-2407-13-243

24 Nykamp K, Anderson M, Powers M, Garcia J, Herrera B, Ho YY, Kobayashi Y, Patil N, Thusberg J, Westbrook M and Topper S: Sherloc: a comprehensive refinement of the ACMG-AMP variant classification criteria. Genet Med 19: 1105-1117, 2017. PMID: 28492532. DOI: 10.1038/gim.2017.37

25 Lau WCY, Li Y, Liu Z, Gao Y, Zhang Q and Huen MSY: Structure of the human dimeric ATM kinase. Cell Cycle 15: 1117-1124, 2016. PMID: 27097373. DOI: 10.1080/15384101. 2016.1158362

26 Wojcik P, Jasiowka M, Strycharz E, Sobol M, HodowiczZaniewska D, Skotnicki P, Byrski T, Blecharz P, Marczyk E, Cedrych I, Jakubowicz J, Lubiński J, Sobik V, Narod S and Pierzchalski P: Recurrent mutations of BRCA1, BRCA2 and PALB2 in the population of breast and ovarian cancer patients in Southern Poland. Heredit Cancer Clin Pract 14: 5, 2016. PMID: 26843898. DOI: 10.1186/s13053-016-0046-5

27 Balabas A, Skasko E, Nowakowska D, Niwinska A and Blecharz P: Novel germline mutations in BRCA2 gene among breast and breast-ovarian cancer families from Poland. Fam Cancer 9: 267274, 2010. PMID: 20383589. DOI: 10.1007/s10689-010-9338-5

28 Ratajska M, Brozek I, Senkus-Konefka E, Jassem J, Stepnowska M, Palomba G, Pisano M, Casula M, Palmieri G, Borg A, Limon $\mathrm{J}$ : BRCA1 and BRCA2 point mutations and large rearrangements in breast and ovarian cancer families in Northern Poland. Oncol Rep 19: 263-268, 2008. PMID: 18097605.

29 Zhang F, Ma J, Wu J, Ye L, Cai H, Xia B and Yu X: PALB2 links BRCA1 and BRCA2 in the DNA-damage response. Curr Biol 19: 524-529, 2009. PMID: 19268590. DOI: 10.1016/ j.cub.2009.02.018
30 Nowacka-Zawisza M, Raszkiewicz A, Kwasiborski T, Forma E, Bryś M, Różański W and Krajewska WM: RAD51 and XRCC3 polymorphisms are associated with increased risk of prostate cancer. J Oncol 2019: 1-8, 2019. PMID: 31186630. DOI: $10.1155 / 2019 / 2976373$

31 Blanco A, Gutiérrez-Enríquez S, Santamariña M, Montalban G, Bonache S, Balmaña J, Carracedo Á, Diez O and Vega A: RAD51C germline mutations found in Spanish site-specific breast cancer and breast-ovarian cancer families. Breast Cancer Res Treat 147: 133-143, 2014. PMID: 25086635. DOI: 10.1007/s10549-014-3078-4

32 Romero A, Pérez-Segura P, Tosar A, García-Saenz JA, DíazRubio E, Caldés T and de la Hoya M: A HRM-based screening method detects RAD51C germ-line deleterious mutations in Spanish breast and ovarian cancer families. Breast Cancer Res Treat 129: 939-946, 2011. PMID: 21537932. DOI: 10.1007/ s10549-011-1543-X

33 Osorio A, Endt D, Fernández F, Eirich K, de la Hoya M, Schmutzler R, Caldéz T, Meindl A, Schindler D, Benitez J: Predominance of pathogenic missense variants in the RAD51C gene occurring in breast and ovarian cancer families. Hum Mol Genet 21: 2889-2898, 2012. PMID: 22451500. DOI: 10.1093/ $\mathrm{hmg} / \mathrm{dds} 115$

34 Gruver AM, Miller KA, Rajesh C, Smiraldo PG, Kaliyaperumal S, Balder R, Stiles KM, Albala JS and Pittman DL: The ATPase motif in RAD51D is required for resistance to DNA interstrand crosslinking agents and interaction with RAD51C. Mutagenesis 20: 433-440, 2005. PMID: 16236763. DOI: 10.1093/mutage/ gei059

35 Tung N, Lin NU, Kidd J, Allen BA, Singh N, Wenstrup RJ, Hartman A-R, Winer EP and Garber JE: Frequency of germline mutations in 25 cancer susceptibility genes in a sequential series of patients with breast cancer. J Clin Oncol 34: 1460-1468, 2016. PMID: 26976419. DOI: 10.1200/JCO.2015.65.0747

36 Balmaña J, Digiovanni L, Gaddam P, Walsh MF, Joseph V, Stadler ZK, Nathanson KL, Garber JE, Couch FJ, Offit K, Robson ME and Domchek SM: Conflicting interpretation of genetic variants and cancer risk by commercial laboratories as assessed by the prospective registry of multiplex testing. J Clin Oncol 34: 4071-4078, 2016. PMID: 27621404. DOI: 10.1200/ JCO.2016.68.4316

37 Yurgelun MB, Allen B, Kaldate RR, Bowles KR, Judkins T, Kaushik P, Roa BB, Wenstrup RJ, Hartman AR and Syngal S: Identification of a variety of mutations in cancer predisposition genes in patients with suspected Lynch syndrome. Gastroenterology 149: 604-613.e20, 2015. PMID: 25980754. DOI: $10.1053 /$ j.gastro.2015.05.006

38 Viniegra JG, Martínez N, Modirassari P, Losa JH, Cobo CP, Lobo VJS-A, Luquero CIA, Álvarez-Vallina L, Ramón y Cajal S, Rojas JM and Sánchez-Prieto R: Full activation of PKB/Akt in response to insulin or ionizing radiation is mediated through ATM. J Biol Chem 280: 4029-4036, 2005. PMID: 15546863. DOI: $10.1074 / j b c . M 410344$

Received March 19, 2020

Revised March 30, 2020

Accepted March 31, 2020 